Article

\title{
Biofuels from Diethyl Carbonate and Vegetable Oils for Use in Triple Blends with Diesel Fuel: Effect on Performance and Smoke Emissions of a Diesel Engine
}

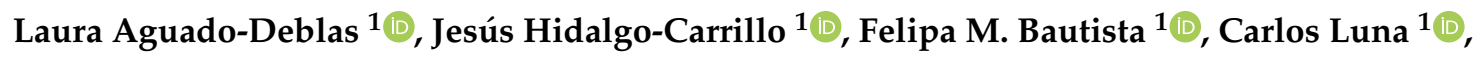 \\ Juan Calero $^{1}$, Alejandro Posadillo ${ }^{2}$, Antonio A. Romero ${ }^{1}\left(\mathbb{D}\right.$, Diego Luna $^{1, *(\mathbb{D})}$ and \\ Rafael Estévez ${ }^{1}$ \\ 1 Departamento de Química Orgánica, Campus de Rabanales, Universidad de Córdoba, Ed. Marie Curie, \\ 14014 Córdoba, Spain; aguadolaura8@gmail.com (L.A.-D.); Jesus.hidalgo@uco.es (J.H.-C.); \\ qo1baruf@uco.es (F.M.B.); qo2luduc@uco.es (C.L.); p72camaj@gmail.com (J.C.); qo1rorea@uco.es (A.A.R.); \\ q72estor@uco.es (R.E.) \\ 2 Seneca Green Catalyst S.L., Campus de Rabanales, 14014 Córdoba, Spain; seneca@uco.es \\ * Correspondence: diego.luna@uco.es; Tel.: +34-957-212-065
}

Received: 5 November 2020; Accepted: 9 December 2020; Published: 14 December 2020

check for updates

\begin{abstract}
The main objective of this work is to contribute to a gradual replacement process of fossil diesel (D) with biofuels composed by diethyl carbonate (DEC) and either sunflower or castor oil, as straight vegetable oils (SVOs). DEC is a very interesting candidate as an oxygenated additive not only because of its low price and renewable nature, but also its favorable fuel properties, such as very low kinematic viscosity, high cetane number, high oxygen content, rich cold flow properties and good miscibility with fossil diesel and vegetable oils. In this work, the more suitable DEC/SVO biofuels are chosen based on kinematic viscosity, according to the European normative. Additionally, the most relevant physical-chemical properties of (bio)fuels such as density, calorific value, cloud point, pour point and cetane number are determined. The influence of DEC on engine performance and exhaust emissions is analyzed by fueling a conventional Diesel engine with the different $\mathrm{D} / \mathrm{DEC} / \mathrm{SVO}$ triple and DEC/SVO double mixtures. The tests results are also compared with commercial diesel. From the results, it is concluded that Diesel engine fueled with the blends studied exhibits an excellent performance in terms of power output, very similar to diesel. Additionally, the use of these blends can remarkably decrease smoke emissions down to $98 \%$, with respect to fossil diesel. The addition of DEC shows a significant improvement in cold flow properties of fuel mixtures in the exchange of a slightly higher brake specific fuel consumption (BSFC) than diesel. Interestingly, the pure biofuels composed by DEC and SVO allow for a suitable engine operation and achieve the lowest emissions, which means these blends can be successfully employed in current engines without adding fossil diesel, i.e., their use entail a $100 \%$ renewability.
\end{abstract}

Keywords: diethyl carbonate; sunflower oil; castor oil; straight vegetable oils; soot emissions; biofuel; fuel blends; diesel engine; power output; BSFC

\section{Introduction}

The so-called Paris Agreement, established at the last Paris climate conference (COP21) in December of 2015, unified, for the first time to all countries of the world, to adopt a set of actions on climate change, among them, reducing greenhouse gas (GHG) emissions [1]. Since the $\mathrm{CO}_{2}$ emissions, responsible for about $80 \%$ of GHG, come mainly from the transportation sector, the search for renewable liquid biofuels as alternatives to fossil fuels is vital [2]. Although there are new green alternatives, such as electric or hydrogen engines, these are still far from replacing combustion engines, especially in 
heavy vehicles [3], the aviation sector [4] and the shipping sector [5]. Therefore, the energy transition process to replace fossil fuels with others of renewable character must be carried out with vehicles currently in circulation, which incorporate engines designed to work with fossil fuels.

In this context, vegetable oils (VOs) emerge as an important renewable alternative to replace fossil diesel because these are produced easily at low cost and also exhibit similar characteristic to diesel. However, the high viscosity of VOs does not allow for their use as biofuels in compression ignition (C.I.) diesel engines [6]. To make VOs compatible with current diesel engines, according to the European Normative (EN590), different strategies to reduce their viscosities are under study. In this sense, the most commonly accepted option has been the transformation of different oils into biodiesel, through a triglyceride's transesterification process with methanol. In fact, biodiesel has become the most used liquid biofuel. The main limitation is the high amount of glycerol obtained as a by-product, around $10-20 \%$ by weight of biodiesel, which causes the contamination of biodiesel. Thus, there is the need for purification by successive washing with water (using an average of four liters per liter of purified biodiesel), in order to fulfill the limit established by EN14214 ( $<0.25 \mathrm{wt}$.\%). Thus, the technical complexity of the process limits its economic viability in such a way that the price of biodiesel has increased dramatically by 1.5-3.0 times the price of fossil diesel. For this reason, the option of using vegetable oils as a raw material for the production of biofuels is gaining importance [7].

The direct use of oils by blending with low viscosity solvents (LVSs) has been recently investigated. This new eco-friendly procedure allows us to produce biofuels that can be directly applied in existing diesel engines, without any mechanical modification [8]. On the one hand, this methodology overcomes operational problems associated with the use of crude vegetable oil in diesel engines, i.e., the fuel poor atomization and the formation of deposits in the injector. On the other hand, besides viscosity, the use of appropriate fuel additives can improve lubricity, cetane number, cold flow properties, and so on, which provides a positive effect on engine performance [9]. In the last decade, multiple LVSs have been proposed to obtain viscosity values of SVOs that fulfill the range 2.0-4.5 cSt imposed by normative EN590. These solvents usually exhibit low viscosity values, low energy density, and sometimes, low cetane number, so that they have been called LVLC (Low Viscosity and Low Cetane) fuels [10]. Thus, several short-chain alcohols (methanol, ethanol and n-butanol) [10-13], light vegetable oils (camphor, eucalyptus, pine and orange oils) $[10,14-17]$ and, even non-renewable biofuels, such as gasoline $[18,19]$, have been employed as effective LVLC fuels, giving rise to very good results.

Furthermore, others organic compounds that can be obtained from renewable sources, including diethyl ether [20-22], acetone [23] and ethyl acetate [24], have been very recently reported as excellent solvents of sunflower or castor oil for use in diesel engines, being part of ternary blends with fossil diesel. The studied blends led to a high substitution level of fossil diesel fuel. Likewise, the incorporation of these biofuels, obtained by blending oxygenated compounds and SVOs, in addition to notably decreased exhaust emissions from diesel engines, improved cold flow properties as well as the engine performance, which was similar to that obtained with commercial diesel [22-24]. However, it was found that a high percentage of oxygenated compound in the blends reduces the power output of the engine and, in some cases, results in to engine detonation problems due to its low calorific value. Therefore, the proportion of biofuel that can be incorporated into the blend is limited [22].

In this line, several studies have reported diethyl carbonate as an effective oxygenated additive in proportions of up to $20 \%$ for fossil diesel, resulting in lower soot and NOx emissions emitted by the engine, as well as an improved engine performance [25-28]. The effect DEC on the performance and emission of a diesel engine has been also analyzed on blends with waste plastic oil and diesel. This work revealed improvements in brake thermal efficiency and a reduction in both BSFC and engine exhaust emissions by using DEC [29]. DEC is a non-toxic and biodegradable compound that exhibits very attractive properties as an oxygenated additive, including high oxygen content, excellent miscibility with fossil diesel, good cold flow properties, high cetane number, and so on (Table 1). In addition, DEC can be directly synthetized though an environment friendly process, from bioethanol and $\mathrm{CO}_{2}$, which contributes significantly to the reduction in atmospheric $\mathrm{CO}_{2}$ [30]. Notwithstanding its 
promising properties as biofuel, to the best of our knowledge, there are no previous works addressing DEC as a solvent for vegetable oils for use in diesel engines.

Table 1. Properties of diesel, sunflower oil, castor oil, and diethyl carbonate. Density and kinematic viscosity are experimentally obtained, whereas the other data are taken from the literature [27,31,32].

\begin{tabular}{ccccc}
\hline Property & Diesel & Sunflower Oil & Castor Oil & DEC \\
\hline Density at $15{ }^{\circ} \mathrm{C}\left(\mathrm{kg} / \mathrm{m}^{3}\right)$ & 820 & 865 & 898 & 964 \\
Kinematic viscosity at $40{ }^{\circ} \mathrm{C}(\mathrm{cSt})$ & 3.20 & 37.80 & 226.20 & 0.82 \\
Oxygen content $(\mathrm{wt} . \%)$ & 0 & 10 & 15 & 40.7 \\
Calorific value $(\mathrm{MJ} / \mathrm{L})$ & 35.1 & 34.3 & 35.5 & 20.3 \\
Flash point $\left({ }^{\circ} \mathrm{C}\right)$ & 66 & 220 & 228 & 25 \\
Auto-ignition temperature $\left({ }^{\circ} \mathrm{C}\right)$ & 250 & 316 & 448 & 445 \\
Cetane number & 51 & 37 & 40 & 58 \\
\hline
\end{tabular}

The present investigation evaluates the influence of using diethyl carbonate, as a low viscosity solvent of sunflower and castor oil, to obtain alternative biofuels as a replacement for fossil diesel. Hence, the analysis of performance and soot emissions from a Diesel engine operating on diesel/DEC/SVO and DEC/SVO (bio)fuels has been carried out. Experimental tests have been also conducted with conventional diesel for comparison reasons. Moreover, the most relevant properties of blends have been determined to evaluate their influence on operational parameters of engine. The reformulation of diesel fuel is realized by adding of $20 \%, 40 \%, 60 \%$ and $80 \%$ of the ideal DEC/SVO double mixtures to commercial diesel (B20-B80 blends). Moreover, pure DEC/SVO biofuels (B100SO and B100CO blends) has been tested on a diesel engine.

\section{Materials and Methods}

2.1. Preparation of Diethyl Carbonate/Vegetable Oil Double Blends, and Diesel/Diethyl Carbonate/Vegetable Oil Triple Blends

Sunflower oil (reference of waste cooking oil) was purchased from a local market, Castor oil and diethyl carbonate (purity $\geq 99.5 \%$ ) were purchased from Panreac (Castellar Del Valles, Spain) and Sigma-Aldrich Chemical Company, respectively. Diesel was obtained from a Repsol service station. The DEC/SVO double blends were prepared by mixing either sunflower or castor oil with DEC in different proportions.

Diesel/DEC/SVO triple blends were prepared by the addition of diesel to the double blends that meet the requirements of the EN-590 ISO-3104. Different amounts of renewable biofuel (DEC/SVO mixture) of triple blends are expressed in $v / v \%$. These mixtures containing sunflower and castor oil are termed as BXSO and BXCO, respectively, where $\mathrm{X}$ is the percentage of biofuel added into the mixture. The employed percentages of biofuel were $20 \%, 40 \%, 60 \% 80 \%$ and $100 \%$. Additionally, commercial diesel (represented as B0) was subjected to experimental tests to obtain reference results.

\subsection{Characterization of the Chemical-Physical Properties of the (Bio)Fuel Blends}

Some of the physicochemical properties that more significantly affect to the behavior of mixtures as (bio)fuels in diesel engines are experimentally determined or calculated using predictive equations. All the experimental measurements here reported are the media of three determinations and the errors are indicated as standard deviation.

\subsubsection{Density and Kinematic Viscosity Measurements}

The pure components as well as the different blends were cooled down to $15{ }^{\circ} \mathrm{C}$ and then, density measurements were carried out according to the EN ISO 3675 test method.

Kinematic viscosity was determined in accordance with the European standard's requirements (EN 590 ISO 3104). For that, the methodology described in previous research was used [19,22-24]. 
Thus, kinematic viscosity was measured in an Ostwald-Cannon-Fenske capillary viscometer (Proton Routine Viscometer 33,200 , size 150 ) working at $40{ }^{\circ} \mathrm{C}$. The kinematic viscosity (v) in centistokes (cSt) or $\mathrm{mm}^{2} / \mathrm{s}$, is obtained by means of Equation (1):

$$
v=\mathrm{C} \cdot \mathrm{t}
$$

where $C$ is the constant of calibrated viscometer, supplied by the manufacturer $\left(0.037150\left(\mathrm{~mm}^{2} / \mathrm{s}\right) / \mathrm{s}\right.$ at $40{ }^{\circ} \mathrm{C}$ ) and $\mathrm{t}$ is the flow time; namely, the time in seconds that a known volume of liquid takes to pass, under action of gravity, between two marks indicated on an instrument.

\subsubsection{Cloud Point and Pour Point Measurements}

The cold flow properties were determined, as specified by standard methods EN 23015/ASTM D2500, for cloud point, and ISO 3016/ASTM D97, for pour point. A previously reported methodology was employed [19,22-24].

\subsubsection{Determination of Calorific Value}

Calorific value (CV), also called heat of combustion, was determined following the Kay Mixing rule [33], from the volumetric fraction of each component in the blend, $\mathrm{Xi}$, and the calorific value of each component, CVi (Equation (2)):

$$
\mathrm{CV}=\sum_{\mathrm{i}} \mathrm{CViXi}
$$

The CV has been expressed in MJ/L using the experimental density obtained for each mixture.

\subsubsection{Determination of Cetane Number}

Cetane number $(\mathrm{CN})$ of mixtures was calculated from the volumetric fraction of every component, $\mathrm{X} i$, and the cetane number of each component, $\mathrm{CNi}$ [33] by means of Equation (3):

$$
\mathrm{CN}=\sum_{\mathrm{i}} \mathrm{CNiXi}
$$

\subsection{Analysis of Performance and Exhaust Emissions from Diesel Engine-Electrogenerator Set}

The study of performance, from power output and brake-specific fuel consumption, as well as smoke emissions of a diesel engine-electric generator set have been explored following the experimental methodology previously reported [15-17]. The technical specifications of engine are displayed in Table 2 and the experimental methodology is illustrated in Figure 1. The compression-ignition engine used in this work is a 4-stroke and single-cylinder with cylinder dimensions of $78 \mathrm{~mm}$ bore and $67 \mathrm{~mm}$ stroke. The engine has a forced air-cooling system by flywheel fan. All engine parameters are keeping identical in each test, i.e., there are no modifications in the diesel engine during the tests. Therefore, the tests with the different fuel blends are conducted under the same engine operation conditions, but at different load conditions $(0,1,2,3,4$ and $5 \mathrm{~kW})$. The engine load is the power demanded by the engine, which is applied by connecting heating plates (1000 W each one) to the engine. The engine speed is always kept at a constant value of $3000 \mathrm{rpm}$. The amount of fuel employed in each test is 0.5 L. Before each test, the engine is running for $20 \mathrm{~min}$ to achieve stable conditions. Between each test, the engine is fueled with diesel and works for $20 \mathrm{~min}$ to purge from the system the possible remaining fuel tested. The power output of the engine is calculated from the amperage and voltage generated, which are measured by means of a voltmeter-ammeter. 
Table 2. Technical specifications of the Diesel Engine-Electrogenerator Set.

\begin{tabular}{cc}
\hline Model & AYERBE 4000 Diesel \\
\hline Alternator & LINZ-SP 10MF 4.2 KVA \\
Engine & YANMAR LN-70 \\
Type & Vertical cylinder, 4-cycle, air-cooled diesel engine \\
Combustion & Direct injection \\
Bore $\times$ Stroke & $78 \times 67 \mathrm{~mm}$ \\
Displacement & $320 \mathrm{~cm}^{3}$ \\
Horsepower & 6.7 \\
Rated power output & $4.5 \mathrm{~kW} / 3000 \mathrm{rpm}$ \\
Voltage & $230 \mathrm{~V}$ \\
Fuel consumption & $1.3 \mathrm{~L} / \mathrm{H}(75 \%)$ \\
\hline
\end{tabular}

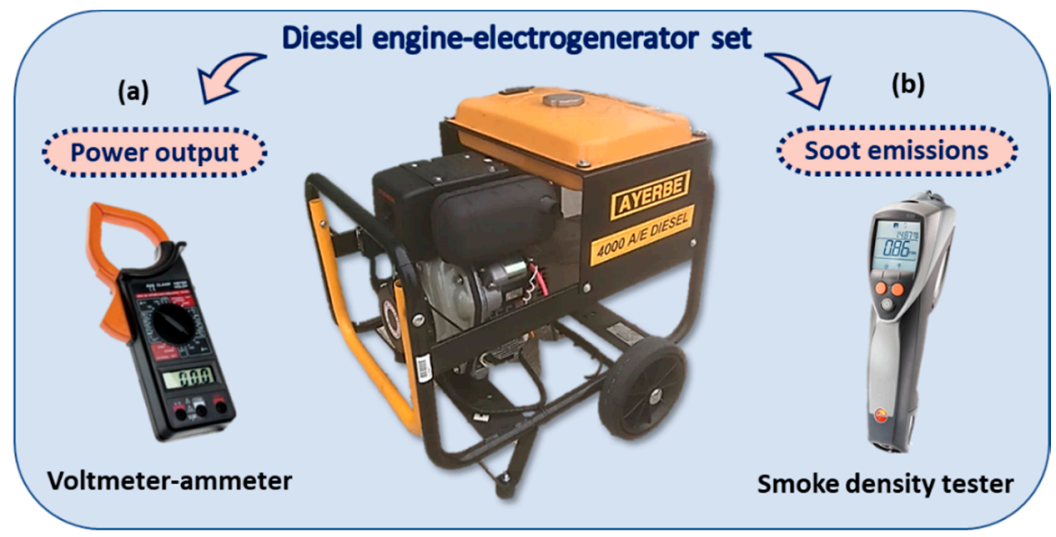

Figure 1. Scheme of methodology on a Diesel Engine-Electrogenerator Set to determine (a) power output by using a voltmeter-ammeter devise; (b) generated soot emissions by using smoke density tester.

The contamination levels were obtained from the opacity of the generated smoke during the combustion process. In this investigation, smoke density in the flue gases was measured with an opacimeter-type TESTO 338 density gauge (or smoke density tester), following the standard method ASTM D-2156. The instrument calculates the smoke density from the level of soot on a filter paper. The smoke emissions are expressed in soot concentration $\left(\mathrm{mg} / \mathrm{m}^{3}\right)$. The measurement range for smoke density is from 0 to $50 \mathrm{mg} / \mathrm{m}^{3}$, where 0 indicates absolute clarity on the paper and 50 represents $100 \%$ of blackening. The repeatability is of $\pm 0.5 \mathrm{mg} / \mathrm{m}^{3}( \pm 9 \%)$. The analyzer is calibrated with zero gas before each test.

The BSFC, expressed in $\mathrm{g} / \mathrm{h} \cdot \mathrm{kW}$, is the mass of fuel consumed by the engine at a certain time and at certain power output. BSFC is calculated measuring the volume consumed by the engine fueled with the different (bio)fuels at a certain time. The used volume for each measure was $0.5 \mathrm{~L}$. The BSFC measurements were carried out at 1,3 and $5 \mathrm{~kW}$ of engine load, which represent low, medium and high-power demands. All of tests were done three times, showing the results as averaged along with standard deviation, displayed as error bars.

\section{Results and Discussion}

\subsection{Physicochemical Properties of Diethyl Carbonate/Vegetable Oil and Diesel/Diethyl Carbonate/Vegetable Oil Blends}

As can be seen in Table 3, the blending of the vegetable oils with a low viscous solvent, such as DEC in proper proportions, allows us to obtain suitable viscosity values for the use of both castor oil and sunflower oil as biofuels in today's Diesel engines. In this way, the main obstacle of these oils, which is the high viscosity, is overcome. 
Table 3. Kinematic viscosity at $40{ }^{\circ} \mathrm{C}$ in centiStokes (cSt) of diethyl carbonate (DEC)/sunflower oil (SO) and diethyl carbonate (DEC)/castor oil (CO) double blends. The error is expressed as standard deviation.

\begin{tabular}{ccc}
\hline \multicolumn{3}{c}{ Kinematic Viscosity (cSt) } \\
\hline \multirow{2}{*}{ Diethyl Carbonate (\% by Volume) } & \multicolumn{2}{c}{ Biofuel Blend } \\
\cline { 2 - 3 } & DEC/SO & DEC/CO \\
\hline 0 & $37.80 \pm 0.46$ & $226.20 \pm 0.55$ \\
20 & $14.50 \pm 0.10$ & $38.07 \pm 0.09$ \\
40 & $6.15 \pm 0.04$ & $11.70 \pm 0.03$ \\
50 & $4.42 \pm 0.03$ & $5.51 \pm 0.02$ \\
60 & $3.58 \pm 0.02$ & $3.59 \pm 0.04$ \\
10 & $1.67 \pm 0.05$ & $2.45 \pm 0.08$ \\
& $0.82 \pm 0.03$ & $0.82 \pm 0.03$ \\
\hline
\end{tabular}

The results show that suitable viscosity values of 4.42 and $3.59 \mathrm{cSt}$ are obtained by using $50 \%$ and $60 \%$ DEC in double blends with sunflower and castor oil, respectively. Therefore, the blends DEC/SO $50 / 50$ and DEC/CO 60/40 comply with the requisites established by the European standard EN 590 ISO 3104 , since their viscosity values are found in the range 2.0-4.5 cSt. It is remarkable how DEC has a stronger effect on castor oil than on sunflower oil to diminish its very high initial viscosity $(226.20 \mathrm{cSt})$ by six times $(38.07 \mathrm{cSt}$ ) when $20 \%$ DEC is added. On the other hand, the viscosity of sunflower oil also suffers a drastic drop, from 37.80 to $14.50 \mathrm{cSt}$ (three times lower), with the same amount of DEC (20\%). The behavior has been also observed in previous works, where other compounds were investigated as viscosity improvers of SVOs, including diethyl ether [22], acetone [23] or ethyl acetate [24].

The effect of adding the DEC/SO and DEC/CO biofuels (containing 50\% and $60 \%$ of DEC, respectively) to fossil diesel in proportions between $20 \%$ and $80 \%$ volumes (from B20 to B80), is studied through the analysis of different properties that notably influence the final performance of the diesel engine. Thereby, the results related to density, kinematic viscosity, calorific value, cetane number, cloud point and pour point of blends are listed in Tables 4 and 5 .

Table 4. Fuel properties of diesel (B0), DEC/SO double blend (B100) and D/DEC/SO triple blends (B20-B80), containing 50\% DEC. Experimental data are showed along with the standard deviation obtained from average of three measurement.

\begin{tabular}{cccccccc}
\hline $\begin{array}{c}\text { Fuel } \\
\text { Blend }\end{array}$ & D/DEC/SO & $\begin{array}{c}\text { Kinematic } \\
\text { Viscosity }(\mathbf{c S t})\end{array}$ & $\begin{array}{c}\text { Density at 15 } \\
{ }^{\circ} \mathbf{C}\left(\mathbf{k g} / \mathbf{m}^{\mathbf{3}}\right)\end{array}$ & $\begin{array}{c}\text { Cloud } \\
\text { Point }\left({ }^{\circ} \mathbf{C}\right)\end{array}$ & $\begin{array}{c}\text { Pour } \\
\text { Point }\left({ }^{\circ} \mathbf{C}\right)\end{array}$ & $\begin{array}{c}\text { Calorific } \\
\text { Value }(\mathbf{M J} / \mathbf{L})\end{array}$ & $\begin{array}{c}\text { Cetane } \\
\text { Number }\end{array}$ \\
\hline B0 & $100 / 0 / 0$ & $3.20 \pm 0.03$ & $820 \pm 6$ & $-6.0 \pm 1.0$ & $-16.0 \pm 1.2$ & 35.10 & 51.00 \\
$\mathrm{~B} 20 S O$ & $80 / 10 / 10$ & $3.22 \pm 0.03$ & $836 \pm 5$ & $-11.0 \pm 1.3$ & $-21.3 \pm 0.7$ & 33.70 & 50.30 \\
$\mathrm{~B} 40 S O$ & $60 / 20 / 20$ & $3.30 \pm 0.05$ & $857 \pm 5$ & $-10.6 \pm 1.1$ & $-19.8 \pm 1.0$ & 32.41 & 49.60 \\
$\mathrm{~B} 60 S O$ & $40 / 30 / 30$ & $3.53 \pm 0.04$ & $875 \pm 3$ & $-9.3 \pm 0.8$ & $-17.6 \pm 1.0$ & 30.91 & 48.90 \\
$\mathrm{~B} 80$ SO & $20 / 40 / 40$ & $3.71 \pm 0.03$ & $892 \pm 3$ & $-8.8 \pm 0.9$ & $-17.3 \pm 0.9$ & 29.29 & 48.20 \\
$\mathrm{~B} 100 S O$ & $0 / 50 / 50$ & $4.42 \pm 0.03$ & $915 \pm 4$ & $-8.0 \pm 1.0$ & $-16.8 \pm 1.1$ & 27.77 & 47.50 \\
\hline
\end{tabular}

Table 5. Fuel properties of diesel (B0), DEC/CO double blend (B100) and D/DEC/CO triple blends (B20-B80), containing 60\% DEC. Experimental data are shown along with the standard deviation obtained from average of three measurement.

\begin{tabular}{|c|c|c|c|c|c|c|c|}
\hline $\begin{array}{l}\text { Fuel } \\
\text { Blend }\end{array}$ & D/DEC/CO & $\begin{array}{c}\text { Kinematic } \\
\text { Viscosity (cSt) }\end{array}$ & $\begin{array}{c}\text { Density at } 15 \\
{ }^{\circ} \mathrm{C}\left(\mathrm{kg} / \mathrm{m}^{3}\right)\end{array}$ & $\begin{array}{c}\text { Cloud } \\
\text { Point }\left({ }^{\circ} \mathrm{C}\right)\end{array}$ & $\begin{array}{c}\text { Pour } \\
\text { Point }\left({ }^{\circ} \mathrm{C}\right)\end{array}$ & $\begin{array}{c}\text { Calorific } \\
\text { Value }(\mathrm{MJ} / \mathrm{L})\end{array}$ & $\begin{array}{l}\text { Cetane } \\
\text { Number }\end{array}$ \\
\hline B0 & $100 / 0 / 0$ & $3.20 \pm 0.03$ & $820 \pm 6$ & $-6.0 \pm 1.0$ & $-16.0 \pm 1.2$ & 35.10 & 51.00 \\
\hline B20CO & $80 / 12 / 8$ & $3.21 \pm 0.02$ & $844 \pm 4$ & $-13.0 \pm 0.8$ & $-21.7 \pm 0.5$ & 33.70 & 50.96 \\
\hline B40CO & $60 / 24 / 16$ & $3.25 \pm 0.05$ & $866 \pm 3$ & $-12.2 \pm 1.0$ & $-21.0 \pm 0.7$ & 32.10 & 50.92 \\
\hline B60CO & $40 / 36 / 24$ & $3.33 \pm 0.06$ & $889 \pm 4$ & $-12.0 \pm 0.9$ & $-18.7 \pm 0.7$ & 30.40 & 50.88 \\
\hline B80CO & $20 / 48 / 32$ & $3.40 \pm 0.03$ & $915 \pm 4$ & $-11.5 \pm 0.8$ & $-18.0 \pm 0.4$ & 28.67 & 50.84 \\
\hline B100CO & $0 / 60 / 40$ & $3.59 \pm 0.04$ & $937 \pm 5$ & $-13.5 \pm 1.0$ & $-19.0 \pm 1.0$ & 26.67 & 50.80 \\
\hline
\end{tabular}


The viscosity of each triple blend, from B20 to B80, increases as the DEC/SVO biofuel amount increases in the fuel mixture. This fact is expected, since the B100SO and B100CO renewable biofuels exhibit slightly higher viscosities (4.42 and $3.59 \mathrm{cSt}$ ) than diesel (3.20 cSt, B0). In general, viscosities vary in the range of 3.22-3.71 cSt for D/DEC/SO triple blends and 3.21-3.40 cSt for the analogous blends with castor oil, and then the proposed blends adjust to European regulations (EN 590) to their enforcement on diesel engines.

The density of each blend fuel, which has a direct influence on engine performance characteristics, such as cetane number and calorific value, is also presented in Tables 4 and 5. Independent of the vegetable oil employed, as the DEC/SVO biofuel fraction increases in the blend, a higher density is observed. In general, these were density values varying between 836 and $892 \mathrm{~kg} / \mathrm{m}^{3}$ for BXSO mixtures and between 844 and $915 \mathrm{~kg} / \mathrm{m}^{3}$ for BXCO mixtures. The highest density was exhibited by biofuels DEC/SO and DEC/CO at 915 and $937 \mathrm{~kg} / \mathrm{m}^{3}$, respectively. The maximum absolute error in the measurements was $0.7 \%$.

Regarding cold flow properties (Tables 4 and 5), the use of DEC as a solvent of sunflower and castor oil, produces a noticeable improvement in both pour point and cloud point of all blends. In fact, the minimum proportion of DEC/SVO biofuel into the blend (20\%) achieves the lowest temperature values in B20SO and B20CO triple mixtures, which exhibit a PP of -21.3 and $-21.7^{\circ} \mathrm{C}$, as well as a $\mathrm{CP}$ of -11.0 and $-13.0^{\circ} \mathrm{C}$, respectively. In this way, $\mathrm{PP}$ and $\mathrm{CP}$ are reduced down to 5.3 and $5{ }^{\circ} \mathrm{C}$ by the addition of $10 \%$ DEC and 10\% SO (B20SO mixture). The decrease in flow temperature is even higher for mixtures containing $\mathrm{CO}$, which achieve a reduction in $\mathrm{PP}$ and $\mathrm{CP}$ down to 5.7 and $7^{\circ} \mathrm{C}$ (B20CO mixture) with respect to fossil diesel. This behavior is similar to that previously found using diethyl ether [22], acetone [23] or ethyl acetate [24], as an additive in triple mixtures, along with the same vegetable oils and fossil diesel.

On the other hand, the calorific values of the fuels, which is an essential parameter for engine performance, were determined and the results are displayed in Tables 4 and 5 . As the percentage of DEC in the mixtures is increased, a gradual reduction in calorific value is produced in comparison to the diesel calorific value. This fact is expected because the calorific values of the tested vegetable oils and, especially DEC (20.3 MJ/L, Table 1), is lower than that of diesel (35.1 MJ/L, Table 1). Generally, the greater oxygen content in triple blends, as a consequence of incorporating DEC and SO or CO, the lower the calorific power of the fuel blends. This behavior has also been observed in previous investigations [22-24]. Despite the fact that the low calorific power of DEC could constitute the main handicap for its use as biofuel, the proposed blending method with plant oils and diesel in the right proportions was not conducted to big losses in energy content and so, high substitution values can be achieved at the same time, as long as a good engine performance is maintained. Thus, the highest calorific value for the blends containing either sunflower (Table 4) or castor oil (Table 5), is found with the lowest ratio of DEC, i.e., $10 \%$ for B20SO (33.7 MJ/L) and 12\% for B20CO (33.7 MJ/L). The similar calorific values of sunflower and castor oil, 34.3 and $35.5 \mathrm{MJ} / \mathrm{L}$, respectively, leads to only minor differences between both vegetable oils. In general, the energy content of the mixtures B20SO-B100SO is around $4-21 \%$ lower than diesel, whereas that of the B20CO-B100CO mixtures is $5-24 \%$ lower than diesel for both cases.

The cetane number of each double and triple mixture is indicated in Tables 4 and 5 as well. Generally, an increase in the ratio DEC/SVO, from $20 \%$ to $80 \%$ in the triple blends, involves a reduced cetane number. However, it is noteworthy that the cetane numbers of all proposed triple blends are very close to that of commercial diesel, especially for the mixtures containing castor oil. Thus, the cetane number for CO blends oscillates between 50.30 and 47.50 (B20SO-B100SO), while that of B20CO-B100CO biofuel mixtures is found in the range 50.96-50.80. Taking account that all of the studied fuels have a cetane number below 51, which is the minimum established in the European standard (EN 14214), a slightly longer ignition delay is expected, in comparison with the reference diesel.

The results demonstrate the synergy effect between the components in the blends. The addition of DEC not only improves the kinematic viscosity of vegetable oils, which allows for their use as 
drop-in biofuels for fueling current diesel engines, but also improves cetane number and the behavior of fuel blends at cold climates. For its part, vegetable oils compensate the low energy density of DEC. In addition to these advantages, its high oxygen content ( $40.7 \%$ by weight), as well as its non-toxic and biodegradable nature, make diethyl carbonate a very promising biofuel.

\subsection{Performance of a Diesel Engine Fueled with DEC/SVO and D/DEC/SVO (Bio)Fuels Blends}

\subsubsection{Power Output}

Figure 2 displays the variation in power output of engine fueled with the different triple mixtures composed by either sunflower oil (B20SO-B80SO), shown in Figure 2a, and castor oil (B20CO-B80CO), shown in Figure $2 b$, with engine loads of $0-5 \mathrm{~kW}$ and at same engine working conditions (Table 2). Additionally, the engine performances with diesel fossil fuel and the pure biofuels, B100SO and $\mathrm{B} 100 \mathrm{CO}$, are included as references for comparison. It is observed that power output slightly decreased as the percentage of DEC/SVO biofuel increases. This behavior can be attributed to the lower energy content of the proposed blends, in comparison to that of commercial diesel, as a consequence of the incorporation of diethyl carbonate, which exhibits a lower calorific value of $20.3 \mathrm{MJ} / \mathrm{L}$ (Table 1). Hence, the power output is decreased by $3-31 \%$ when blends containing sunflower oil are supplied to the engine (Figure 2a), whereas the blends with castor oil exhibit a reduction in the power output of 4-34\%, as compared to diesel (Figure 2b). Nonetheless, it is remarkable how all studied blends give rise to power output values very similar and even, in some cases, better than those obtained with diesel. This is the case of the B20CO blend, which generates a power of around 4-9\% higher than that of diesel at high engine loads (4 and $5 \mathrm{~kW}$ ). Likewise, the B40SO blend presents an increase in power output of about $2 \%$ with respect to diesel when the highest demand of power is applied to engine ( $5 \mathrm{~kW})$. On the other hand, if the use of both vegetable oils is compared, a slightly greater efficiency with mixtures that contain castor oil can be noted, probably because of their higher cetane number, which improves the ignition quality of fuel. Related to the impact of engine load on power output, it can be confirmed that, in general, when diesel fossil, or any of the evaluated (bio)fuels, are employed, the power output is higher, as the demanded power to engine is increased from 0 to $4 \mathrm{~kW}$, while a rise in the power supply $(5 \mathrm{~kW})$ involves a slight drop in the output power of the engine. It is really interesting to note the fact that the pure biofuels, formulated exclusively with renewable compounds, although with a slight loss of power with respect to mixtures containing diesel, conducted through proper engine operation.

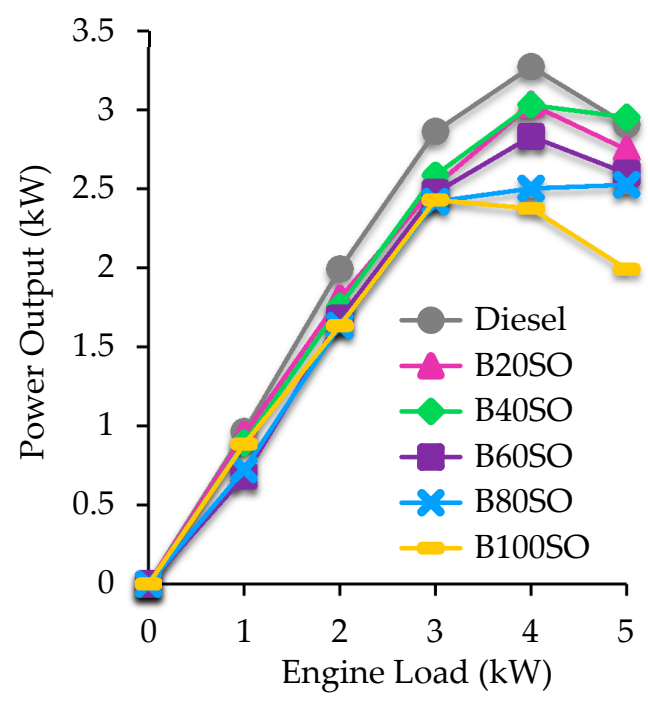

(a)

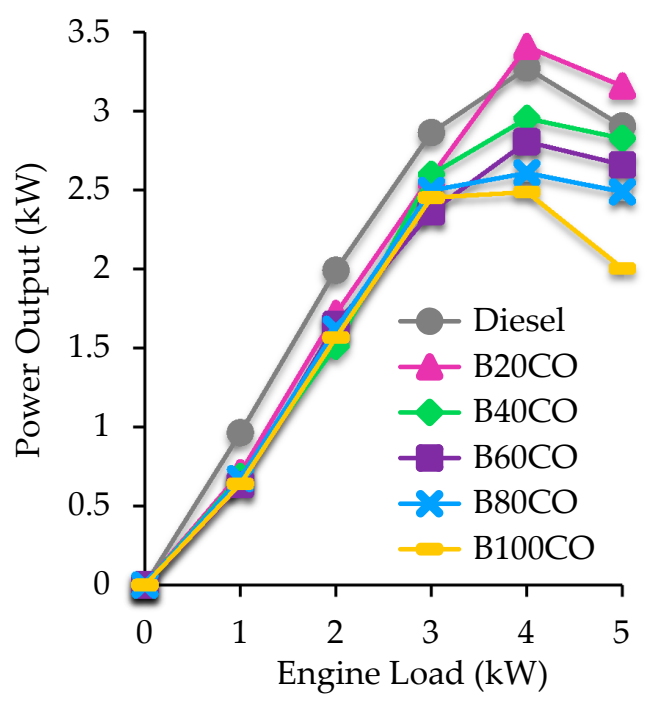

(b)

Figure 2. Power Output (W) versus engine load (0-5 kW), for the fuel blends: (a) DEC/SO and $\mathrm{D} / \mathrm{DEC} / \mathrm{SO}$; (b) DEC/CO and D/DEC/CO. The errors in measurements are less than $3 \%$. 


\subsubsection{Brake-Specific Fuel Consumption (BSFC)}

BSFC relates the consumed fuel by the engine with the power that it produces. This is an essential parameter to compare the efficiency of the engine. Figure 3 illustrates BSFC versus loads applied to engine $(1,3$ and $5 \mathrm{~kW})$ at constant operation conditions. A similar trend is observed with all tested fuel blends at the different loads. As expected, the BSFC values obtained at low engine loads $(1 \mathrm{~kW})$ were higher than those obtained at medium or high loads ( 3 and $5 \mathrm{~kW})$. The decrease in the BSFC values as the engine load increases has been previously explained by the fact that an increase in the load raises the in-cylinder temperature, thus improving the combustion process [34]. A stabilization in BSFC happens when the highest engine load $(5 \mathrm{~kW})$ is applied. Overall, the results obtained show that the substitution of fossil diesel by the tested fuel blends at any load, involves an increment in BSFC, independently of used vegetable oil. This is ascribed to the lower energy content of the blends containing DEC, since its calorific value is considerably lower than that of diesel fuel (Table 1). Additionally, the higher density of the blends in comparison with diesel involves a larger volume of fuel introduced into the cylinder, which causes an increase in BSFC. Therefore, the engine needs a higher volume of fuel to attain the corresponding power output when it is fueled with the blends containing SVOs and DEC. However, there are no major differences between the fuel blends and diesel at medium and high loads. In fact, BSFC values are very similar to those of diesel in B20 and B40 fuels in cases where they contain either SO or CO. Since these blends exhibit comparable cetane number and lower calorific value with diesel, its better behavior can be explained by the presence of oxygen in its composition, which contributes towards improving the combustion reaction and, as a result, the power output of the engine is enhanced. In this way, the oxygen content of fuel mixtures overcomes the reduction in calorific value. Nevertheless, the influence of other factors, such as boiling point, viscosity, auto-ignition temperature, etc., cannot be ruled out. On the other hand, the slightly higher BSFC of the mixtures composed by castor oil (Figure 3a), compared with sunflower oil (Figure 3b), could be ascribed to the lower energy density of these blends, which reduce the power output of the engine.

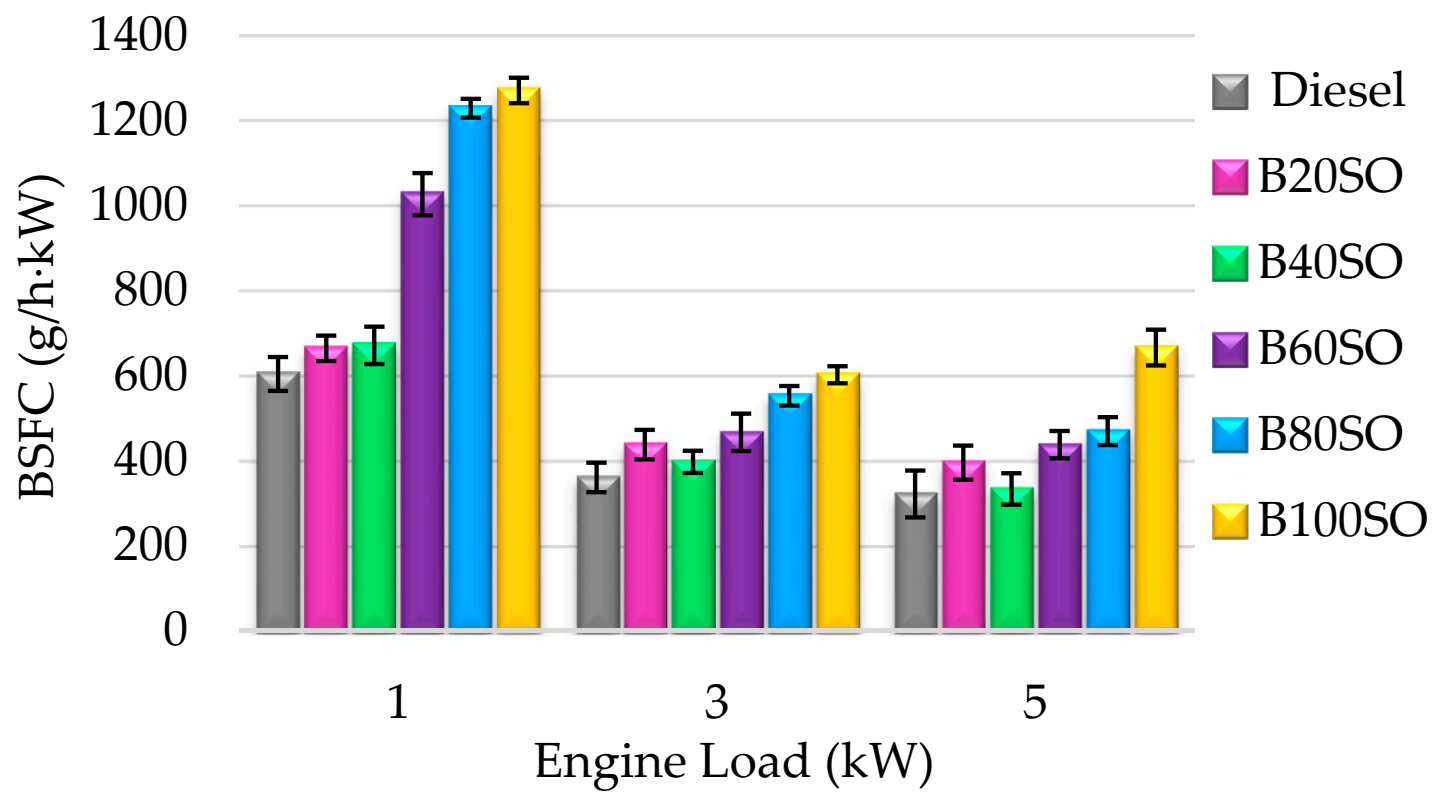

(a)

Figure 3. Cont. 


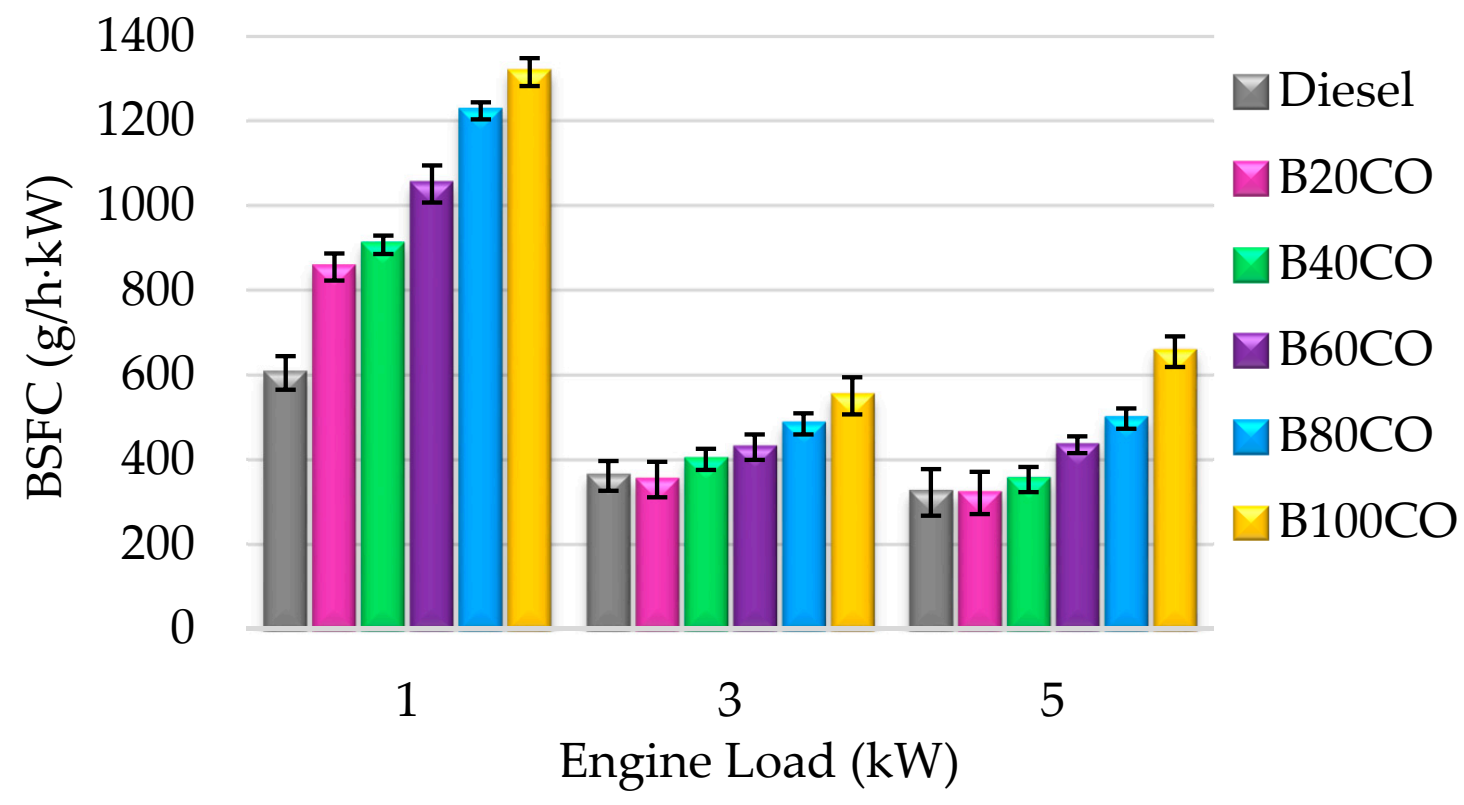

(b)

Figure 3. BSFC $(\mathrm{g} / \mathrm{h} \cdot \mathrm{kW})$ at low, medium and high engine loads $(1,3,5 \mathrm{~kW})$ for the fuel blends: (a) $\mathrm{DEC} / \mathrm{SO}$ and $\mathrm{D} / \mathrm{DEC} / \mathrm{SO}$; (b) DEC/CO and D/DEC/CO. The measure errors are represented as standard deviation using error bars.

\subsection{Exhaust Emissions: Opacity}

The variation in smoke concentration for the different mixtures with sunflower (a) and castor oil (b) at engine loads from 0 to $5 \mathrm{~kW}$ is shown in Figure 4. The results obtained show that all of the $\mathrm{D} / \mathrm{DEC} / \mathrm{SVO}$ blends, as well as the DEC/SVO biofuels, notably reduced soot emissions with respect to conventional diesel. The effect of DEC and SVOs on emissions is even stronger at high engine loads (4 and $5 \mathrm{~kW}$ ). This reduction in smoke emissions, by adding oxygenated compounds to diesel fuel, is usually associated with an improvement in the combustion reaction and the promotion of the oxidation of soot. The oxidation of soot is not only encouraged by the presence of oxygen in the combustion chamber, but also by the longer ignition delay, produced by compounds with a lower cetane number, which provide more time to burn fuel in the premixed combustion phase, and subsequently, more soot particles are oxidized [35]. Thus, when the DEC/SVO biofuels are incorporated to the triple blends, the proportion of oxygen is increased, leading to lower emissions. As it is expected, B100SO and B100CO double blends, that do not contain diesel, achieved the best emission values, since these blends emit up to $74-98 \%$ and $92-98 \%$ less smoke than diesel, respectively. Overall, the percentage of soot reduction ranges from $19-92 \%$ for B20SO-B80SO fuel mixtures, and from $20-95 \%$ for the analogous mixtures that contain castor oil. 


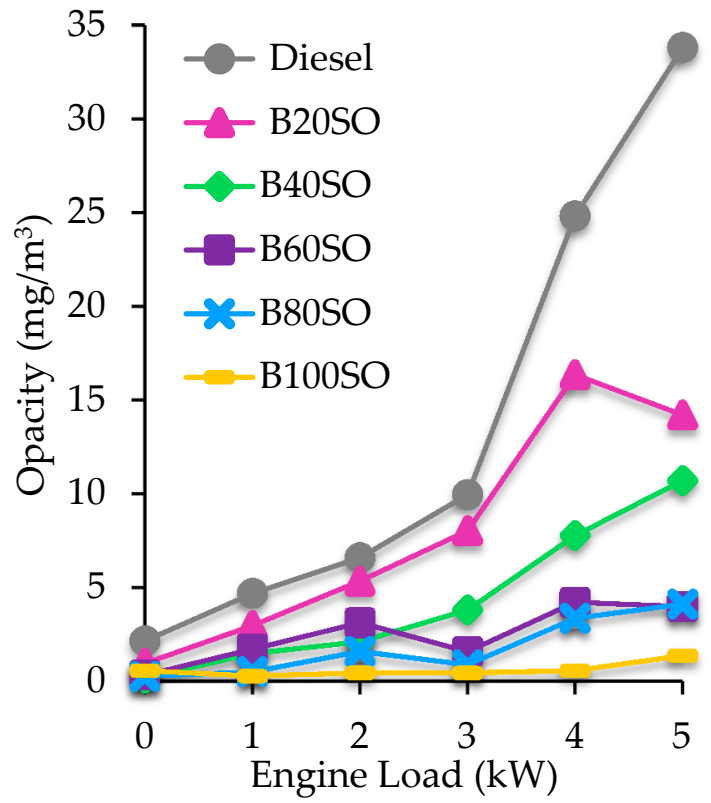

(a)

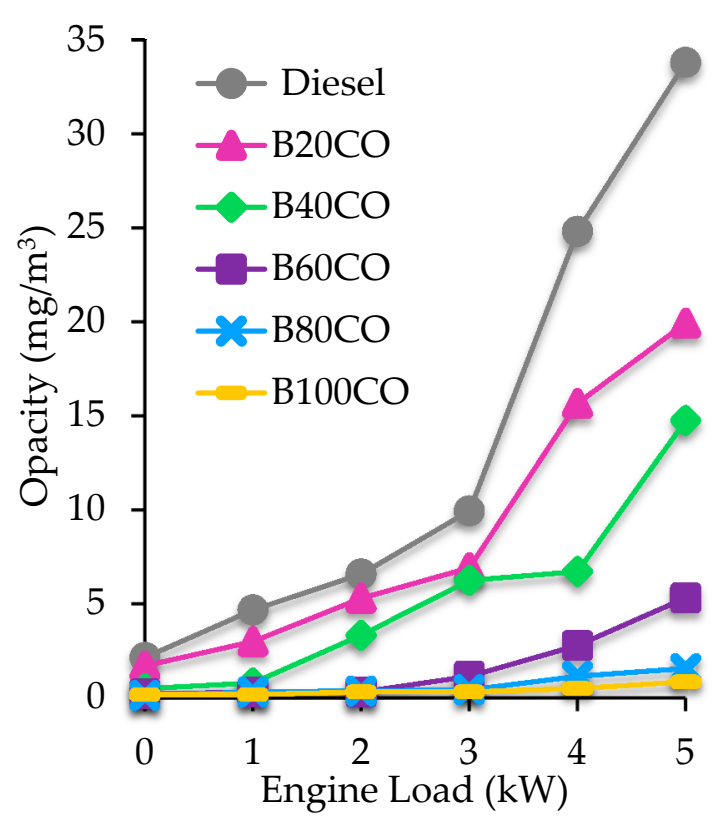

(b)

Figure 4. Opacity values $\left(\mathrm{mg} / \mathrm{m}^{3}\right)$ at engine loads from $0 \mathrm{~kW}$ to $5 \mathrm{~kW}$, for the fuel blends: (a) DEC/SO and D/DEC/SO; (b) DEC/CO and D/DEC/CO.

The presence of unsaturations in a fuel promotes soot formation by increasing the soot precursor species, such as polycyclic aromatic hydrocarbons (PAHs). Hence, the differences in the opacity results of blends with the two evaluated vegetable oils, could be ascribed to the fact that the linoleic acid found in sunflower oil has a greater amount of unsaturations than ricinoleic acid, present in castor oil. The chemical decomposition of these unsaturated compounds generates PAHs that, after being isomerized, began forming into soot [36]. This could explain the worse behavior of sunflower oil in terms of reducing smoke opacity from the diesel engine.

\subsection{Comparison with Previous Research}

The best results related to diesel replacement and reduction in smoke emissions obtained in this work, and with other analogous blends reported in the literature, are collected in Table 6. As can be seen, the best results are obtained with blends containing $100 \%$ diethyl carbonate and any vegetable oil either SO or CO (B100SO and B100CO). These double blends achieve the lowest opacity values; almost $100 \%$ of smoke reduction compared to diesel. Additionally, other LVLC renewable solvents have been employed to reduce the high viscosity of sunflower and castor oil. Thus, the blending of $45 \%$ of ethyl acetate (EA) with CO led to a $100 \%$ diesel replacement and smoke emissions that were $96 \%$ lower than diesel [24]. Despite the good results obtained with EA, the power output with D/EA/SVO triple blends was not as high as that of the triple blends using DEC as a solvent. The use of diethyl ether (DEE) [22] or acetone (ACE) [23] as renewable solvents allowed for the replacement of a maximum of $40 \%$ of diesel, and up to $77 \%$ and $82 \%$ reductions in soot emissions, respectively. Although a good engine performance was reached with these fuel mixtures, the engine did not properly work with amounts of DEE or ACE greater than $40 \%$. This behavior was attributed to the very low calorific value of these oxygenated compounds that decreased the energetic content of the blends. 
Table 6. Comparison between different fuel blends found in the literature and the blends analyzed here, in terms of smoke emissions and percentage of replaced diesel.

\begin{tabular}{ccccc}
\hline Nomenclature & Fuel Blend & Diesel Replacement (\%) & Smoke Opacity * & Reference \\
\hline B100CO & $60 \%$ CO $/ 40 \%$ DEC & 100 & $\downarrow 98 \%$ & Present \\
B100SO & $50 \%$ SO/50\% DEC & 100 & $\downarrow 96 \%$ & study \\
B100 & $55 \%$ CO/45\% EA & $40 \%]$ \\
B40 & $60 \%$ D $/ 18 \%$ & $40 \%$ & $\downarrow 82 \%$ & {$[23]$} \\
B40 & ACE $/ 22 \%$ CO & $40 \%$ D $/ 18 \%$ & $\downarrow 77 \%$ & {$[22]$} \\
\hline
\end{tabular}

* Smoke opacity reduction as compared to diesel.

\section{Conclusions}

The present work has explored the viability of using diethyl carbonate as an alternative fuel by blending with vegetable oils, in order to obtain renewable biofuels that can replace, as much as possible, fossil diesel; that also allows for a reduction in polluting emissions from current diesel vehicles. The obtained results and conclusions are summarized in the following points:

- The addition of diethyl carbonate not only adjusts the kinematic viscosity of vegetable oils to the required values to be European normative, but also noticeably improves the flow behavior of fuels at low temperatures, which is an advantage for a diesel engine working in colder climates.

- The lower energy density in the blended fuels, as the proportion of DEC/SVO is increased, is responsible for slight losses in engine power output, as well as a higher fuel BSFC. Notwithstanding, the higher cetane number of DEC improves the ignition quality of blends, leading to an outstanding performance of the engine with the $\mathrm{B} 20 \mathrm{SO}, \mathrm{B} 40 \mathrm{SO}, \mathrm{B} 20 \mathrm{CO}$ and $\mathrm{B} 40 \mathrm{CO}$ mixtures, which generate a similar or higher power, and a comparable BSFC to diesel, especially at medium and high engine loads.

- The presence of oxygen in the fuels is a crucial factor to achieve low emissions. The incorporation of the new DEC/SVO biofuels to diesel decreases the engine smoke by $92-95 \%$. Additionally, almost zero emissions can be achieved by using DEC/SVO double blends without incorporated fossil diesel. Hence, it was confirmed that oxygen-rich compounds have a crucial function in fuel ignition quality and soot emission reductions.

- In view of the good results obtained with B100SO and B100CO blends, fuels that are $100 \%$ renewable and composed exclusively of diethyl carbonate and vegetable oils, could be directly applied in the present diesel vehicles, which would involve the entire replacement of diesel fossil.

- The carbonylation of ethanol using $\mathrm{CO}_{2}$ to produce DEC is a synthesis method that acts as a sink for $\mathrm{CO}_{2}$. Therefore, it is considered a promising strategy for climate change mitigation.

- Fuel blending is a simple methodology that allows for obtaining fuels from renewable and easily available feedstocks, which entails lower costs and having a lower environmental impact, in comparison with other biofuels found on the market, such as biodiesel. This is definitely a promising methodology to accomplishes high substitution levels of fossil diesel.

- This experimental study represents an advance in searching for alternative biofuels for the transportation sector.

Author Contributions: D.L. designed the study; L.A.-D. performed the experiments and wrote the paper; R.E. reviewed and edited the paper; R.E., D.L., and F.M.B. supervised the study and revised the manuscript; C.L., J.H.-C., J.C., A.P., and A.A.R. made intellectual contributions to this study. All authors have read and agreed to the published version of the manuscript.

Funding: This research received no external funding. 
Acknowledgments: The authors are thankful to MINECO-ENE2016-81013-R (AEI/FEDER, EU), MICIIN (Project ref. PID2019-104953RB-100), the Consejería de Transformación Económica, Industria, Conocimiento y Universidades de la Junta de Andalucía (UCO-FEDER Project CATOLIVAL, ref. 1264113-R, 2018 call and Project ref. P18-RT-4822) and FEDER Funds for financial support. Technical assistance of staff at Central Service for Research Support (SCAI) and Institute of Nanochemistry (IUNAN) of the University of Córdoba is also acknowledged.

Conflicts of Interest: The authors declare no conflict of interest.

\section{Nomenclature}

$\begin{array}{ll}\text { ACE } & \text { Acetone } \\ \text { ASTM } & \text { American society for testing and materials } \\ \text { B0 } & 100 \% \text { diesel } \\ \text { B20CO } & 80 \% \text { diesel }+20 \% \text { diethyl carbonate/castor oil blend } \\ \text { B40CO } & 60 \% \text { diesel }+40 \% \text { diethyl carbonate/castor oil blend } \\ \text { B60CO } & 40 \% \text { diesel }+60 \% \text { diethyl carbonate/castor oil blend } \\ \text { B80CO } & 20 \% \text { diesel }+80 \% \text { diethyl carbonate/castor oil blend } \\ \text { B100CO } & 100 \% \text { diethyl carbonate/castor oil blend } \\ \text { B20SO } & 80 \% \text { diesel }+20 \% \text { diethyl carbonate/sunflower oil blend } \\ \text { B40SO } & 60 \% \text { diesel }+40 \% \text { diethyl carbonate/sunflower oil blend } \\ \text { B60SO } & 40 \% \text { diesel }+60 \% \text { diethyl carbonate/sunflower oil blend } \\ \text { B80SO } & 20 \% \text { diesel }+80 \% \text { diethyl carbonate/sunflower oil blend } \\ \text { B100SO } & 100 \% \text { diethyl carbonate/sunflower oil blend } \\ \text { BSFC } & \text { Brake-specific fuel consumption } \\ \text { C.I. } & \text { Compression ignition } \\ \text { CN } & \text { Cetane number } \\ \text { CO } & \text { Castor oil } \\ \text { CP } & \text { Cloud point } \\ \text { cSt } & \text { Centistokes } \\ \text { CV } & \text { Calorific value } \\ \text { D } & \text { Diesel } \\ \text { DEE } & \text { Diethyl ether } \\ \text { EA } & \text { Ethyl acetate } \\ \text { ISO } & \text { International Standards Organization } \\ \text { LVLC } & \text { Low Viscosity and Low Cetane } \\ \text { LVS } & \text { Low viscosity solvent } \\ \text { PP } & \text { Pour point } \\ \text { rpm } & \text { Round per minute (min-1) } \\ \text { SO } & \text { Sunflower oil } \\ \text { SVO } & \text { Straight vegetable oil } \\ \text { VO } & \text { Vegetable oil } \\ \text { W } & \text { Watts } \\ \text { Symbols } & \\ \text { C } & \\ \text { t } & \text { Calibration constant (mm } 2 / \text { s)/s } \\ v & \text { is } \\ & \end{array}$

\section{References}

1. Rhodes, C.J. The 2015 Paris climate change conference: COP21. Sci. Prog. 2016, 1, 97-104. [CrossRef] [PubMed]

2. Creutzig, F.; Jochem, P.; Edelenbosch, O.Y.; Mattauch, L.; van Vuuren, D.P.; McCollum, D.; Minx, J. Transport: A roadblock to climate change mitigation? Science 2015, 350, 911-912. [CrossRef] [PubMed]

3. Sen, B.; Ercan, T.; Tatari, O. Does a battery-electric truck make a difference?-Life cycle emissions, costs, and externality analysis of alternative fuel-powered Class 8 heavy-duty trucks in the United States. J. Clean. Prod. 2017, 141, 110-121. [CrossRef] 
4. Wang, M.; Dewil, R.; Maniatis, K.; Wheeldon, J.; Tan, T.; Baeyens, J.; Fang, Y. Biomass-derived aviation fuels: Challenges and perspective. Prog. Energy Combust. Sci. 2019, 74, 31-49. [CrossRef]

5. Winnes, H.; Styhre, L.; Fridell, E. Reducing GHG emissions from ships in port areas. Res. Transp. Bus. Manag. 2015, 17, 73-82. [CrossRef]

6. Dabi, M.; Saha, U.K. Application potential of vegetable oils as alternative to diesel fuels in compression ignition engines: A review. J. Energy Inst. 2019, 92, 1710-1726. [CrossRef]

7. Estevez, R.; Aguado-Deblas, L.; Bautista, F.M.; Luna, D.; Luna, C.; Calero, J.; Posadillo, A.; Romero, A.A. Biodiesel at the Crossroads: A Critical Review. Catalysts 2019, 9, 1033. [CrossRef]

8. Shah, P.R.; Gaitonde, U.N.; Ganesh, A. Influence of soy-lecithin as bio-additive with straight vegetable oil on CI engine characteristics. Renew. Energy 2018, 115, 685-696. [CrossRef]

9. Shah, P.R.; Ganesh, A. A comparative study on influence of fuel additives with edible and non-edible vegetable oil based on fuel characterization and engine characteristics of diesel engine. Appl. Therm. Eng. 2016, 102, 800-812. [CrossRef]

10. Vallinayagam, R.; Vedharaj, S.; Yang, W.; Roberts, W.L.; Dibble, R.W. Feasibility of using less viscous and lower cetane (LVLC) fuels in a diesel engine: A review. Renew. Sustain. Energy Rev. 2015, 51, 1166-1190. [CrossRef]

11. Hurtado, B.; Posadillo, A.; Luna, D.; Bautista, F.; Hidalgo, J.; Luna, C.; Calero, J.; Romero, A.; Estevez, R. Synthesis, performance and emission quality assessment of ecodiesel from castor oil in diesel/biofuel/alcohol triple blends in a diesel engine. Catalysts 2019, 9, 40. [CrossRef]

12. Sivalakshmi, S.; Balusamy, T. Performance and emission characteristics of a diesel engine fueled by neem oil blended with alcohols. Int. J. Ambient Energy 2011, 32, 170-178. [CrossRef]

13. Rakopoulos, D.C. Combustion and emissions of cottonseed oil and its bio-diesel in blends with either n-butanol or diethyl ether in HSDI diesel engine. Fuel 2013, 105, 603-613. [CrossRef]

14. Kumar, N.; Bansal, S.; Pali, H.S. Blending of Higher Alcohols with Vegetable Oil-Based Fuels for Use in Compression Ignition Engine; SAE Technical Paper 2015-01-0958; SAE International: Warrendale, PA, USA, 2015.

15. Kasiraman, G.; Nagalingam, B.; Balakrishnan, M. Performance, emission and combustion improvements in a direct injection diesel engine using cashew nut shell oil as fuel with camphor oil blending. Energy 2012, 47, 116-124. [CrossRef]

16. Kommana, S.; Naik Banoth, B.; Radha Kadavakollu, K. Eucalyptus-Palm kernel oil blends: A complete elimination of diesel in a 4-stroke VCR diesel engine. J. Combust. 2015, 2015, 182879-182886. [CrossRef]

17. Prakash, T.; Geo, V.E.; Martin, L.J.; Nagalingam, B. Evaluation of pine oil blending to improve the combustion of high viscous (castor oil) biofuel compared to castor oil biodiesel in a CI engine. Heat Mass Transf. 2019, 55, 1491-1501. [CrossRef]

18. Lakshminarayanan, A.; Olsen, D.B.; Cabot, P.E. Performance and emission evaluation of triglyceride-gasoline blends in agricultural compression ignition engines. Appl. Eng. Agric. 2014, 30, 523-534.

19. Estevez, R.; Aguado-Deblas, L.; Posadillo, A.; Hurtado, B.; Bautista, F.; Hidalgo, J.M.; Luna, C.; Calero, J.; Romero, A.; Luna, D. Performance and emission quality assessment in a diesel engine of straight castor and sunflower vegetable oils, in diesel/gasoline/oil triple blends. Energies 2019, 12, 2181. [CrossRef]

20. Kumar, A.; Rajan, K.; Naraynan, M.R.; Kumar, K.R.S. Performance and Emission Characteristics of a Di Diesel Engine Fuelled with Cashew Nut Shell Oil (CNSO)-Diesel Blends with Diethyl Ether as Additive. Appl. Mech. Mater. 2015, 787, 746-750. [CrossRef]

21. Krishnamoorthi, M.; Malayalamurthi, R. Experimental investigation on the availability, performance, combustion and emission distinctiveness of bael oil/diesel/diethyl ether blends powered in a variable compression ratio diesel engine. Heat Mass Transf. 2018, 54, 2023-2044. [CrossRef]

22. Aguado-Deblas, L.; Hidalgo-Carrillo, J.; Bautista, F.; Luna, D.; Luna, C.; Calero, J.; Posadillo, A.; Romero, A.; Estevez, R. Diethyl ether as an oxygenated additive for fossil diesel/vegetable oil blends: Evaluation of performance and emission quality of triple blends on a diesel engine. Energies 2020, 13, 1542. [CrossRef] 
23. Aguado-Deblas, L.; Hidalgo-Carrillo, J.; Bautista, F.; Luna, D.; Luna, C.; Calero, J.; Posadillo, A.; Romero, A.; Estevez, R. Acetone prospect as an additive to allow the use of castor and sunflower oils as drop-in biofuels in diesel/acetone/vegetable oil triple blends for application in diesel engines. Molecules 2020, 25, 2935. [CrossRef] [PubMed]

24. Aguado-Deblas, L.; Estevez, R.; Hidalgo-Carrillo, J.; Bautista, F.M.; Luna, C.; Calero, J.; Posadillo, A.; Romero, A.A.; Luna, D. Outlook for direct use of sunflower and castor oils as biofuels in compression ignition Diesel engines, being part of diesel/ethyl acetate/straight vegetable oil triple blends. Energies 2020, 13, 4836. [CrossRef]

25. Ren, Y.; Huang, Z.; Miao, H.; Di, Y.; Jiang, D.; Zeng, K.; Liu, B.; Wang, X. Combustion and emissions of a DI diesel engine fuelled with diesel-oxygenate blends. Fuel 2008, 87, 2691-2697. [CrossRef]

26. Arteconi, A.; Mazzarini, A.; Di Nicola, G. Emissions from ethers and organic carbonate fuel additives: A review. Water Air Soil Pollut. 2011, 2021, 405-423. [CrossRef]

27. Rao, P.V.; Ramesh, S.; Kumar, S.A. Kumar Effects of oxygenated additives with diesel on the performance of D I diesel engine. J. Energy Res. Rev. 2019, 2, 1-9. [CrossRef]

28. Kozak, M.; Merkisz, J.; Bielaczyc, P.; Szczotka, A. The Influence of Oxygenated Diesel Fuels on a Diesel Vehicle

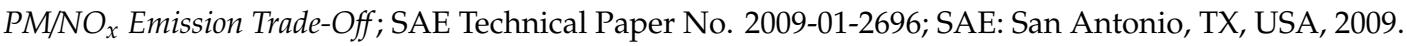

29. Bridjesh, P.; Geetha, N.K. Effect of Diethyl Carbonate as Additive to Waste Plastic Oil on Performance and Emission of a Diesel Engine. Orient. J. Chem. 2020, 36, 189-194. [CrossRef]

30. Shukla, K.; Srivastava, V.C. Diethyl carbonate: Critical review of synthesis routes, catalysts used and engineering aspects. RSC Adv. 2016, 6, 32624-32645. [CrossRef]

31. Ramadhas, A.S.; Jayaraj, S.; Muraleedharan, C. Biodiesel production from high FFA rubber seed oil. Fuel 2005, 84, 335-340. [CrossRef]

32. Keera, S.T.; El Sabagh, S.M.; Taman, A.R. Castor oil biodiesel production and optimization. Egpt. J. Petrol. 2018, 27, 979-984. [CrossRef]

33. Krishnamoorthi, M.; Malayalamurthi, R. Experimental investigation on performance, emission behavior and exergy analysis of a variable compression ratio engine fueled with diesel-aegle marmelos oil-diethyl ether blends. Energy 2017, 128, 312-328. [CrossRef]

34. Venugopal, T.; Ramesh, A. Effective utilisation of butanol along with gasoline in a spark ignition engine through a dual injection system. Appl. Therm. Eng. 2013, 59, 550-558. [CrossRef]

35. Hellier, P.; Ladommatos, N.; Allan, R.; Payne, M.; Rogerson, J. The impact of saturated and unsaturated fuel molecules on diesel combustion and exhaust emissions. SAE Int. J. Fuels Lubr. 2012, 5, 106-122. [CrossRef]

36. Salamanca, M.; Mondragón, F.; Agudelo, J.R.; Benjumea, P.; Santamaría, A. Variations in the chemical composition and morphology of soot induced by the unsaturation degree of biodiesel and a biodiesel blend. Combust. Flame 2012, 159, 1100-1108. [CrossRef]

Publisher's Note: MDPI stays neutral with regard to jurisdictional claims in published maps and institutional affiliations.

(C) 2020 by the authors. Licensee MDPI, Basel, Switzerland. This article is an open access article distributed under the terms and conditions of the Creative Commons Attribution (CC BY) license (http://creativecommons.org/licenses/by/4.0/). 